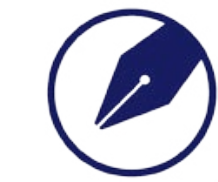

UNIVERSAL WISER

PUBLISHER

\title{
Phytochemicals and Antioxidant Properties of Solvent Extracts from Purslane (Portulaca oleracea L.): A Preliminary Study
}

\author{
Mahmood Habibian*, Ghorbanali Sadeghi, Ahmad Karimi \\ Department of Animal Science, Faculty of Agriculture, University of Kurdistan, Sanandaj, Iran \\ Email: mahmood_habibiyan@yahoo.com
}

\begin{abstract}
A systematic study was conducted about the solvent effect on the purslane total phenolic, flavonoid, alkaloid, carotenoid, saponin, vitamin E, and vitamin C contents as well as to evaluate their contribution to overall antioxidant activity. Among three solvents investigated, water could extract the highest levels of solid and saponin contents, whereas methanol was more effective for obtaining phenolic, flavonoid, and alkaloid compounds than other solvents. Meanwhile, ethanol was the best choice for extracting carotenoids and vitamin E. In various experimental models including DPPH radical scavenging activity, $\mathrm{ABTS}^{+}$radical scavenging activity, and ferric reducing antioxidant power, methanol extract consistently showed significantly greater antioxidant activity than other extracts, while ethanol extract provided the most efficient inhibiting activity against ferrous chloride-induced oxidation of linoleic acid. In addition, the scavenging efficiency of ethanol extract toward DPPH and $\mathrm{ABTS}^{+}$radicals was significantly higher than the water extract, and vice versa was the case for ferric reducing antioxidant power. Overall, methanol was found to be the most favorable solvent for the extraction of phenolic, flavonoid, and alkaloid compounds that are promising as natural antioxidants. However, different solvents may be used to extract specific antioxidant compounds with distinctive antioxidant activity.
\end{abstract}

Keywords: Purslane, extraction, scavenging activity, reducing power, lipid peroxidation

\section{Introduction}

Purslane (Portulaca oleracea L.) is a widely distributed plant which is introduced as one of the most widely used medicinal herbs by the World Health Organization ${ }^{[1]}$, has been given the name "global panacea" ${ }^{[2]}$. The herb is eaten raw as a vegetable or in salads or cooked in soups ${ }^{[3]}$. It has been traditionally used worldwide as a folk medicine to cure a wide range of ailments and disorders such as skin diseases, fever, dysentery, diarrhea, bleeding piles, kidney and liver diseases, coughing, shortness of breath, and asthma ${ }^{[4,5]}$.

In animal models, purslane was found to exhibit a wide range of pharmacological effects, including antibacterial, analgesic, anti-inflammatory, skeletal muscle-relaxant and wound-healing properties ${ }^{[2,6,7]}$. The water and/or alcohol extracts were found to inhibit activities of lipoxygenase and prostaglandin synthetase ${ }^{[8]}$, cisplatin-induced toxicity in embryonic liver ${ }^{[9]}$ and gentamicin nephrotoxicity ${ }^{[10]}$, regulate differentiation and proliferation of cell ${ }^{[1]}$, attenuate hypoxiainduced pulmonary edema ${ }^{[12]}$, and lower the blood glucose and lipid levels ${ }^{[13-15]}$. The underlying mechanisms for these beneficial effects are still elusive, but suggested to be mostly associated with antioxidant activities conferred by the ingredients in this medicinal plant.

Purslane is good source of flavonoids, terpenoids, alkaloids, phenolic acids, saponins, vitamins, and minerals ${ }^{[16]}$. Other components such as $\beta$-carotene, glutathione, melatonin, and high content of n-3 fatty acids also occur in the plant ${ }^{[17]}$. All these compounds together contribute to the antioxidant properties and free-radical scavenging activities of purslane. The radical scavenging action of some flavonoids (kaempferol and quercetin) and alkaloids (oleracein A, oleracein B, and oleracein $\mathrm{E}$ ) isolated from purslane have been reported to be even higher than those of vitamin $\mathrm{C}$ and vitamin $\mathrm{E}^{[18,19]}$. Moreover, a purslane extract has been shown to be superior to vitamin $\mathrm{C}$ and $\beta$-carotene in scavenging reactive oxygen species ${ }^{[20]}$. In addition, the assumption that the beneficial effects of purslane constituents are due to its free-radical scavenging action has been shown in numerous in vitro studies ${ }^{[4,19,21,22,23]}$, and increasing numbers of in vivo studies ${ }^{[2,23,}$ ${ }^{24,25]}$. However, there are some considerations with regard to the seasonal variations and storage conditions of the plant ${ }^{[26]}$. Also, in previous studies different contents of bioactive compounds and different antioxidant powers were observed when extraction of plant bioactive compounds was conducted using different solvents ${ }^{[27,28]}$. 
Herbal bioactive compounds have diverse structures and their extractability and activities in different model systems seems to be strictly dependent on their chemical structure ${ }^{[27]}$. Therefore, different extraction media, i.e. solvent systems, may produce different extract yields with selective recovery of antioxidants; depending upon the structure of antioxidant constituents present in the plant materials. In addition, a number of other factors like non-antioxidant components and the polarity of extracting solvents may interference with the antioxidant determining assays ${ }^{[29]}$. Thus, it is also crucial to evaluate the effect of different solvents on extraction of bioactive compounds and antioxidant properties of purslane to find the most suitable solvent for extraction of bioactive compounds from plant material. Such data are rarely available in the literature.

The work described in this preliminary report was undertaken to evaluate the effects of three extraction solvents (water, methanol, and ethanol) on extraction of total phenolic, flavonoid, alkaloid, carotenoid, saponin, vitamin E, and vitamin $\mathrm{C}$ from purslane herb coupled with determination of antioxidant activity through multiple assays. A more detailed analysis, based on LC-MS/MS (liquid chromatography-tandem mass spectrometry) and GC-MS (gas chromatography/ mass spectrometry) was also performed on the extracts, that will be included in another paper. Insights drawn from this study can be used for further processing steps to prepare bioactive compounds from purslane, which may eventually lead to development of new nutraceutical and pharmaceutical products.

\section{Materials and methods}

\subsection{Chemicals and reagents}

The following chemicals were used for analysis: Folin-Ciocalteu's phenol reagent, sodium carbonate $\left(\mathrm{Na}_{2} \mathrm{CO}_{3}\right)$, gallic acid, sodium nitrite $\left(\mathrm{NaNO}_{2}\right)$, aluminum chloride $\left(\mathrm{AlCl}_{3} \cdot 6 \mathrm{H}_{2} \mathrm{O}\right)$, quercetin, bromothymol blue (BTB), caffeine, $\beta$-carotene, vanillin, aescin, 2,4-dinitrophenylhydrazine, thiourea, cupric sulfate $\left(\mathrm{CuSO}_{4} \cdot 5 \mathrm{H}_{2} \mathrm{O}\right)$, ascorbic acid, bathophenanthroline, pyrogallol, $\alpha$-tocopherol, Tris base, DPPH (1,1-diphenyl-2-picrylhydrazyl radical), potassium persulfate, ABTS (2,2'-azinobis(3-ethylbenzothiazoline-6-sulfonic acid) diammonium salt), linoleic acid, Tween 20 , sodium acetate $\left(\mathrm{CH}_{3} \mathrm{COONa} \cdot 3 \mathrm{H}_{2} \mathrm{O}\right)$, and 2,3,5-triphenyl-1,3,4-triaza-2-azoniacyclopenta-1,4-diene chloride (TPTZ) were purchased from Sigma Chemical Co. (St. Louis, MO). Sodium hydroxide $(\mathrm{NaOH})$, hydrochloric acid (HCL), chloroform, hexane, sulfuric acid $\left(\mathrm{H}_{2} \mathrm{SO}_{4}\right)$, trichloroacetic acid (TCA), sodium hydroxide $(\mathrm{KOH})$, ferric chloride $\left(\mathrm{FeCl}_{3}\right)$, ferrous chloride $\left(\mathrm{FeCl}_{2}\right)$, ferrous sulfate $\left(\mathrm{FeSO}_{4} \cdot 7 \mathrm{H}_{2} \mathrm{O}\right)$, phosphoric acid $\left(\mathrm{H}_{3} \mathrm{PO}_{4}\right)$, and glacial acetic acid were purchased from Merck (Darmstadt, Germany).

\subsection{Plant materials and extraction procedure}

Fresh mature wild purslane plants (Figure 1.) were collected at seedling stage from a local field in Sanandaj (Kurdistan Province, Iran). Whole plant parts (seeds, leaves, stems, and roots) were cleaned from soil particles and other pollutants, dried and finely ground to a size of $2 \mathrm{~mm}$ using a typical mill, and extracted to obtain the purslane water, methanol, and ethanol extracts using a Soxhlet apparatus as described by Peng et al. ${ }^{[30]}$ with some modification. Briefly, $20 \mathrm{~g}$ of the powdered plant materials and $50 \mathrm{~mL}$ of the solvent were loaded in the apparatus and refluxed for $3 \mathrm{~h}$ on a hotplate at $70^{\circ} \mathrm{C}$. The resulting crude extracts were passed through four layers of nylon cloth and then filtered through Whatman No. 1 filter paper (Whatman, Maidstone, UK) to remove the extracted materials. The extract was then centrifuged at $5000 \times \mathrm{g}$ for $5 \mathrm{~min}$ to remove fine colloidal particles and concentrated to dryness under reduced pressure using a rotary evaporator (Heidolph, Hei-Vap, Germany) at $50^{\circ} \mathrm{C}$. The dried extracts were weighed to determine the extractable solid contents (extraction yields) and stored at $4^{\circ} \mathrm{C}$ until further use. 

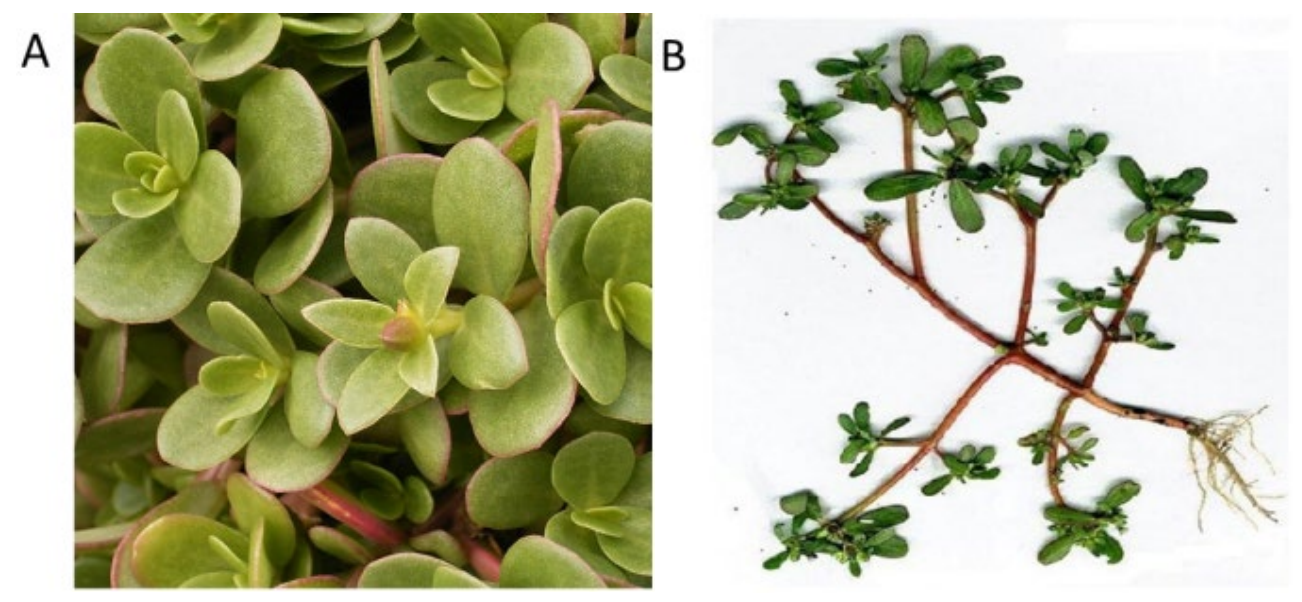

Figure 1. The purslane (Portulaca oleracea L.) plant (A and B)

\subsection{Determination of antioxidant compounds}

Approximately $100 \mathrm{mg}$ of each purslane extract were dissolved in $25 \mathrm{~mL}$ of the respective solvents and quantified spectrophotometrically (Hitachi U-2001, Tokyo, Japan) to determine the content of antioxidant compounds. The following compounds, that are commonly present in purslane, were used as standards: gallic acid, quercetin, caffeine, $\beta$-carotene, aescin, $\alpha$-tocopherol, and ascorbic acid ${ }^{[11,19,31,32,33]}$.

\subsubsection{Total phenolic contents (TPC)}

The TPC of each extract was determined as described elsewhere ${ }^{[34]}$. A $0.5 \mathrm{~mL}$ of sample extract was mixed with 0.5 $\mathrm{mL}$ Folin-Ciocalteu's reagent, followed by addition of $10 \mathrm{~mL}$ of $7 \% \mathrm{Na}_{2} \mathrm{CO}_{3}$ solution. The mixture was incubated for $1 \mathrm{~h}$ at $25^{\circ} \mathrm{C}$ in the dark and then absorbance was measured at $765 \mathrm{~nm}$. The gallic acid standard curve was drawn and the results were expressed as mg of gallic acid equivalents per $\mathrm{g}$ of extract (mg GAE/g dry weight [DW]).

\subsubsection{Total flavonoid contents (TFC)}

The TFC was determined using a colorimetric method described previously ${ }^{[35]}$. A $0.5 \mathrm{~mL}$ of sample extract was mixed with $2.25 \mathrm{~mL}$ of distilled water in a black covered test tube followed by addition of $0.15 \mathrm{~mL}$ of $5 \% \mathrm{NaNO}_{2}$ solution. After $6 \mathrm{~min}, 0.3 \mathrm{~mL}$ of $10 \% \mathrm{AlCl}_{3} \cdot 6 \mathrm{H}_{2} \mathrm{O}$ solution was added and immediately $1.0 \mathrm{~mL}$ of $1 \mathrm{M} \mathrm{NaOH}$ was added. The mixture was vortexed and then absorbance was measured at $510 \mathrm{~nm}$. The quercetin standard curve was plotted and the results were expressed as mg of quercetin equivalents per gram of extract (mg QE/g DW).

\subsubsection{Total alkaloid contents (TAC)}

The TAC was determined according to a method published earlier ${ }^{[36]}$, with some modifications. A $10 \mathrm{~mL}$ of sample extract was dissolved in $15 \mathrm{ml} 2 \mathrm{~N} \mathrm{HCL}$ and then filtered. An aliquot of $10 \mathrm{~mL}$ of this solution was transferred to a separating funnel and washed 3 times with $10 \mathrm{~mL}$ of chloroform. A $5 \mathrm{~mL}$ of $0.1 \%$ chloroform extract was first mixed with $5 \mathrm{~mL}$ of phosphate buffer $(\mathrm{pH} 7.5)$ and $1 \mathrm{~mL}$ of bromothymol blue, and then mixed with $10 \mathrm{~mL}$ of chloroform and shaken for $3 \mathrm{~min}$. After standing for $30 \mathrm{~min}$, the upper chloroform was taken to measure the absorbance at $413 \mathrm{~nm}$. The caffeine standard curve was produced and the results were expressed as mg of caffeine equivalents per gram of extract $(\mathrm{mg} \mathrm{CE} / \mathrm{g}$ DW).

\subsubsection{Total carotenoid contents (TCC)}

The TCC was determined according to a method described previously ${ }^{[22]}$. A $0.5 \mathrm{~g}$ of sample extract was mixed with $15 \mathrm{~mL}$ hexane, vortexed and left for few minutes, then centrifuged for $1 \mathrm{~min}$ at $1500 \times \mathrm{g}$. The supernatant was collected and re-extracted until become colorless. Collected supernatant was evaporated until became dry using a rotary evaporator at $40^{\circ} \mathrm{C}$. Crude extract was re-dissolved in $5 \mathrm{~mL}$ hexane and absorbance was read at $450 \mathrm{~nm}$. The standard curve of $\beta$-carotene was prepared and the results were expressed as $\mathrm{mg}$ of $\beta$-carotene equivalents per gram of extract (mg BCE/g DW).

\subsubsection{Total saponin contents (TSC)}

The TSC was assessed as described before ${ }^{[37]}$. A $0.5 \mathrm{~mL}$ of sample extract was added to $0.5 \mathrm{~mL}$ of $8 \%(\mathrm{w} / \mathrm{v})$ vanillin solution, mixed with $5 \mathrm{~mL}$ of concentrated $\mathrm{H}_{2} \mathrm{SO}_{4}(72 \%)$ and incubated in a water bath at $60^{\circ} \mathrm{C}$ for $15 \mathrm{~min}$, and then cooled on ice to room temperature prior to measurement of absorbance at $560 \mathrm{~nm}$. The standard curve of aescin was constructed and the results were expressed as $\mathrm{mg}$ of aescin equivalents per gram of extract (mg AE/g DW).

\subsubsection{Vitamin C contents}


Vitamin $\mathrm{C}$ content of the extracts was determined using the method described by Awe et al. ${ }^{[38]}$. Briefly, $75 \mu \mathrm{L}$ of DNPH (2 g 2,4-dinitrophenylhydrazine, $230 \mathrm{mg}$ thiourea and $270 \mathrm{mg} \mathrm{CuSO} \cdot 5 \mathrm{H}_{2} \mathrm{O}$ in $100 \mathrm{~mL}$ of $5 \mathrm{M} \mathrm{H}_{2} \mathrm{SO}_{4}$ ) was added to $500 \mu \mathrm{L}$ reaction mixture $(300 \mu \mathrm{L}$ of appropriate dilution of the extracts with $100 \mu \mathrm{L} 13.3 \%$ trichloroacetic acid (TCA) and $100 \mu \mathrm{L}$ water). The reaction mixture was subsequently incubated for $3 \mathrm{~h}$ at $37^{\circ} \mathrm{C}$, then $0.5 \mathrm{~mL}$ of $65 \% \mathrm{H}_{2} \mathrm{SO}_{4}(\mathrm{v} / \mathrm{v}$ ) was added to the medium and absorbance was measured at $520 \mathrm{~nm}$. The vitamin $\mathrm{C}$ content of the extracts was calculated using ascorbic acid as standard and the results were expressed as $\mathrm{mg}$ of ascorbic acid equivalents per gram of extract (mg AAE/g DW).

\subsubsection{Vitamin E contents}

The extracts were screened for vitamin E contents using a method previously described ${ }^{[39]}$. Briefly, $500 \mu \mathrm{L}$ of sample extract was saponified by mixing with a $2 \%$ pyrogallol solution $(5 \mathrm{~mL})$ and heated for 2 min in a $70^{\circ} \mathrm{C}$ shaking water bath. The tubes were removed, and $0.25 \mathrm{~mL}$ of $11 \mathrm{~N} \mathrm{KOH}$ was added. The tubes were heated again in a shaking $70^{\circ} \mathrm{C}$ water bath for $30 \mathrm{~min}$, and placed in an ice bath. In order to vitamin E extraction, $2 \mathrm{~mL}$ of hexane and $0.5 \mathrm{~mL}$ of water were added to the saponified samples and shaken vigorously for $2 \mathrm{~min}$. One milliliter of the hexane layer was transferred to a 4-mL glass test tube for analysis. A $0.2 \%$ bathophenanthroline solution $(200 \mu \mathrm{L})$ was added to all the samples and thoroughly mixed. Two hundred microliters of $1 \mathrm{mM} \mathrm{FeCl}_{3}$ was added and samples were vortexed. After $1 \mathrm{~min}, 200 \mu \mathrm{L}$ of the $\mathrm{H}_{3} \mathrm{PO}_{4}$ solution was added, vortexed again, and the absorbance measured at $534 \mathrm{~nm}$. The standard curve of $\alpha$-tocopherol was used to calculate the vitamin E contents of each sample and results were expressed as $\mathrm{mg}$ of $\alpha$-tocopherol equivalents per gram of extract (mg ATE/g DW).

\subsection{Determination of antioxidant activities}

The antioxidant potential of all the extracts was assessed by DPPH and ABTS radical cation scavenging, lipid oxidation inhibition, and ferric reducing/antioxidant power (FRAP) assays. A stock solution of $500 \mu \mathrm{g} / \mathrm{mL}$ of each extract was prepared by dissolving $5 \mathrm{mg}$ of the extract in $10 \mathrm{~mL}$ of the respective solvents. Other concentrations $(400,300,250$, $200,150,100,75,50$, and $25 \mu \mathrm{g} / \mathrm{mL}$ ) of each extract were prepared freshly with the respective solvents and were used for further assays. These concentrations were selected to ensure that the antioxidant activity of the extracts could be monitored at high and low concentrations. Also, we assumed that such range of concentrations is useful for smooth calculation of $\mathrm{IC}_{50}$ values. Ascorbic acid was used as standard. Absorbance spectra were measured by using a spectrophotometer (Hitachi U-2001, Tokyo, Japan).

\subsubsection{DPPH radical scavenging activity}

The DPPH radical scavenging activity was assessed with minor modification of a reported procedure ${ }^{[40]}$. Briefly, 50 $\mu \mathrm{L}$ of various concentrations $(25-500 \mu \mathrm{g} / \mathrm{mL})$ of each extract and ascorbic acid were taken in a series of test tubes. The volumes were adjusted to $500 \mu \mathrm{L}$ by adding Tris-HCl buffer (pH 7.4). A $1 \mathrm{~mL}$ of a $0.1 \mathrm{mM}$ methanolic solution of DPPH was added to these tubes, which were vigorously shaken. The control was prepared as described above without any extract and distilled water was used for the baseline correction. After $10 \mathrm{~min}$ incubation period in darkness at room temperature, the resultant absorbance was read at $517 \mathrm{~nm}$. Percent inhibition of DPPH was calculated as follows:

Inhibition $(\%)=\left[\left(\mathrm{C}_{\mathrm{abs}}-\mathrm{S}_{\mathrm{abs}}\right) / \mathrm{C}_{\mathrm{abs}}\right] \times 100$

where $\mathrm{C}_{\mathrm{abs}}$ is the control absorbance and $\mathrm{S}_{\mathrm{abs}}$ is the sample absorbance. The concentration that provided $50 \%$ inhibition ( $\mathrm{IC}_{50}$ ) was calculated from the graph with inhibition plotted against extract concentration.

\subsubsection{ABTS radical cation scavenging activity}

The $\mathrm{ABTS}^{+}$radical scavenging activity was measured using a standardized protocol ${ }^{[41]}$. Stock solutions of $7 \mathrm{mM}$ ABTS ((2,2'-azino-bis(3-ethylbenzothiazoline-sulfonic acid) diammonium salt) and $2.45 \mathrm{mM}$ potassium persulfate were prepared in water and kept in the dark for $12 \mathrm{~h}$. Equal volumes of the stock solutions are mixed and diluted to absorbance of $0.70 \pm 0.02$ at $734 \mathrm{~nm}$ to prepare $\mathrm{ABTS}^{+}$radical solution. A $50 \mu \mathrm{L}$ of various concentrations $(25-500 \mu \mathrm{g} / \mathrm{mL})$ of each extract, ascorbic acid, or control ( $50 \mu \mathrm{L}$ of distilled water) was mixed with $\mathrm{ABTS}^{+}$radical solution $(1 \mathrm{~mL})$ and immediately the time was taken and the absorbance was read after $10 \mathrm{~min}$ at $734 \mathrm{~nm}$. The sample absorbance was compared with the control absorbance. Percent inhibition and $\mathrm{IC}_{50}$ values were then measured and calculated as described for DPPH.

\subsubsection{Lipid oxidation inhibition}

The Lipid oxidation inhibition assay was measured as described previously ${ }^{[42]}$. First, the linoleic acid solution was prepared by placing $0.56 \mathrm{~g}$ of linoleic acid and $1.5 \mathrm{~g}$ of Tween $20 \mathrm{in} 8 \mathrm{~mL}$ of ethanol $(96 \%, \mathrm{v} / \mathrm{v})$. Then, $50 \mu \mathrm{L}$ of various concentrations $(25-500 \mu \mathrm{g} / \mathrm{mL})$ of each extract and ascorbic acid were mixed with linoleic acid solution $(100 \mu \mathrm{L})$ and acetate buffer $(1.5 \mathrm{~mL}, 0.02 \mathrm{M}, \mathrm{pH} 4.0)$. Controls contained $50 \mu \mathrm{L}$ of distilled water. The samples were vortex mixed and incubated at $37^{\circ} \mathrm{C}$ for $1 \mathrm{~min}$. Once achieved $1 \mathrm{~min}, 750 \mu \mathrm{L}$ of $50 \mathrm{M} \mathrm{FeCl}_{2}$ solution $\left(0.0994 \mathrm{~g} \mathrm{FeCl}_{2}\right.$ and $0.168 \mathrm{~g}$ EDTA diluted to $1 \mathrm{~L}$ with distilled water) were added to induce the lipid oxidation and incubated for $24 \mathrm{~h}$ at $37^{\circ} \mathrm{C}$. Two aliquots $(250$ 
$\mu \mathrm{L}$ ) were withdrawn during this period, at 1 and $24 \mathrm{~h}$. Each aliquot was processing in the moment as follows: the aliquots were added to $\mathrm{NaOH}$ solution $(1 \mathrm{~mL}, 0.1 \mathrm{M}$, in ethanol at $10 \%, \mathrm{v} / \mathrm{v})$ to stop the oxidation process; after ethanol $(2.5 \mathrm{~mL}$, $10 \%, \mathrm{v} / \mathrm{v})$ was placed to dilute the sample. Then, absorbance of the samples was measured at $232 \mathrm{~nm}$. Ethanol $(10 \%, \mathrm{v} / \mathrm{v})$ was used as blank. Percent inhibition of linoleic acid oxidation was calculated with the following equation:

Lipid oxidation inhibition $(\%)=[(\mathrm{A}-\mathrm{B}) / \mathrm{A}] \times 100$

where $\mathrm{A}$ is the difference between the absorbance of the control sample after $24 \mathrm{~h}$ and $1 \mathrm{~h}$ of incubation, and $\mathrm{B}$ is the difference between the absorbance of each extract sample after $24 \mathrm{~h}$ and $1 \mathrm{~h}$ of incubation. The concentration that provided $50 \%$ inhibition $\left(\mathrm{IC}_{50}\right)$ was calculated from the graph with inhibition plotted against extract concentration.

\subsubsection{FRAP (Ferric reducing/antioxidant power) assay}

The FRAP assay was conducted based on the procedure described by Benzie and Strain ${ }^{[43]}$. A working FRAP solution was freshly prepared by mixing $300 \mathrm{mM}$ acetate buffer $\left(3.1 \mathrm{~g} \mathrm{CH}_{3} \mathrm{COONa} \cdot 3 \mathrm{H}_{2} \mathrm{O}\right.$ was added to $16 \mathrm{~mL}$ of glacial acetic acid and diluted to $1 \mathrm{~L}$ with distilled water), $10 \mathrm{mM} \mathrm{TPTZ}$ in $40 \mathrm{mM} \mathrm{HCl}$, and $20 \mathrm{mM} \mathrm{FeCl}{ }_{3} \cdot 6 \mathrm{H}_{2} \mathrm{O}$ in the ratio of 10:1:1 and warmed at $37^{\circ} \mathrm{C}$ in a water bath before used. A $100 \mu \mathrm{L}$ of each extract and ascorbic acid were mixed with $3 \mathrm{~mL}$ of working FRAP reagent and absorbance of the reaction mixture at $593 \mathrm{~nm}$ was measured at 0 minute after vortexing. Thereafter, samples were placed at $37^{\circ} \mathrm{C}$ in water bath and absorption was again measured after 4 min. A reagent blank was prepared as above with $100 \mu \mathrm{L}$ of distilled water added instead of the test sample. To construct the calibration curve, five concentrations of $\mathrm{FeSO}_{4} \cdot 7 \mathrm{H}_{2} \mathrm{O}(100$ to $2000 \mu \mathrm{M} / \mathrm{L})$ were used and absorbance were measured as sample solution. The values were expressed as $\mathrm{mM}_{\text {of }} \mathrm{FeSO}_{4}$ equivalents per gram of sample (FSE/g DW).

\subsection{Statistical analysis}

All assays were conducted in six replicates and the results are expressed as mean values \pm standard deviations. The data were subjected to ANOVA, and the significance of the difference between means was determined by Tukey's test ( $\mathrm{p}<$ 0.05) using SAS software (SAS Institute, 2003). Pearson's test was used to assess correlations between variables.

\section{Results and discussion}

\subsection{Extractable solid contents}

The results showed that extraction solvents significantly affected extractable solids of purslane herbs. Water was demonstrated to be the most suitable solvent to obtain the highest amount of solids $(11.8 \pm 0.11 \%)$, followed by methanol $(10.5 \pm 0.10 \%)$, and ethanol, which resulted in the lowest extractable solid contents $(7.4 \pm 0.08 \%)$. A similar result has been found by Lim and Quah ${ }^{[45]}$ that water and methanol extracts of purslane herbs had higher extraction yields than ethanol extracts. In addition, Uddin et al. ${ }^{[4]}$ found that water was better solvent for the highest extraction yield of purslane leaves in comparison with methanol.

\subsection{Phytochemical analysis}

The results indicated that extraction solvents also markedly affected extractable amounts of TPC, TFC, TAC, TCC, TSC, and vitamin E (Table 1.). Methanol extract had higher amounts of TPC, TFC, and TAC compared with water and ethanol extracts, but no difference was observed between the levels of these compounds in water and ethanol extracts. In all three extracts, the amounts of TPC were higher than the amounts of TFC and TAC, supporting the fact that most purslane flavonoids and alkaloids are also phenolics ${ }^{[18]}$. Our results are consistent with previous reports that showed that methanol and water are more suitable solvents than ethanol for extraction of phenolic compounds from purslane, while methanol is the most suitable solvent ${ }^{[4,45]}$. The solubility of phenolic compounds is dependent on the polarity of the solvent used, the degree of phenolic polymerization, the interaction of the phenolics with other plant constituents, and the formation of insoluble complexes ${ }^{[46]}$. Tan et al. ${ }^{[47]}$ found that phenolic compounds were much better extracted with the use of polar solvents, whereas methanol was the solvent of choice for extraction of the maximum amount of flavonoids. The structural studies revealed that solubility of phenolic compounds is dependent on their ability to form hydrogen bonds with the surrounding solvent. However, even though flavonoids contain oxygen atoms for hydrogen bonding to water, most of flavonoids are nonpolar in nature and this could be why they are more soluble in methanol than in water ${ }^{[48]}$. The higher level of TPC in methanol extract than water extract, despite higher polarity of water, can also be related to the inhibitory action of methanol on the enzyme polyphenol oxidase ${ }^{[49]}$, which catalyzes two types of oxidative reactions: hydroxylation of monophenols to o-diphenols and oxidation of catechols to o-quinones, which are highly reactive compounds ${ }^{[50]}$. More importantly, o-quinones can easily combine with proteins to form insoluble complexes ${ }^{[51]}$.

In the case of TCC and vitamin E contents, ethanol was better solvent than water and methanol to extract these components. Also, methanol was better than water for extraction of TCC and vitamin E from purslane. On the other hand, 
water was the better solvent than methanol and ethanol to extract TSC from the samples, while ethanol extraction provided the lowest amount of TSC. These effects are in accord with the degree of polarity of the extraction solvent. Vitamin E and most of carotenoids have non-polar and hydrophobic nature ${ }^{[52]}$, whereas saponins are molecules consisting of hydrophilic and hydrophobic segments ${ }^{[33]}$. Generally, saponins are water-soluble thanks to the hydrophilic sugar chain(s) in their structures. Moreover, the amphiphilic nature of these molecules grants them the capacity to self-micellate, which increases their dispersion in the aqueous media ${ }^{[54]}$. However, variable results of water and alcohol solubility depending on the type of saponin have been described ${ }^{[60,68]}$. Vitamin $\mathrm{C}$ was not detected in the extracts, probably due to long extraction time and high temperature ${ }^{[26]}$.

Table 1. Phytochemical composition of purslane extracts

\begin{tabular}{cccc}
\hline Item $^{\text {d,e }}$ & Water extract & Methanol extract & Ethanol extract \\
\hline Total phenolics content, mg GAE/g extract & $57.6 \pm 1.06^{\mathrm{b}}$ & $142.2 \pm 3.83^{\mathrm{a}}$ & $56.2 \pm 1.06^{\mathrm{b}}$ \\
Total flavonoids content, mg QE/g extract & $41.6 \pm 6.17^{\mathrm{b}}$ & $81.2 \pm 1.85^{\mathrm{a}}$ & $42.9 \pm 0.28^{\mathrm{b}}$ \\
Total alkaloids content, mg CE/g extract & $6.8 \pm 0.27^{\mathrm{b}}$ & $15.1 \pm 0.10^{\mathrm{a}}$ & $6.9 \pm 0.09^{\mathrm{b}}$ \\
Total carotenoids content, mg BCE/g extract & $18.9 \pm 0.60^{\mathrm{c}}$ & $27.0 \pm 0.58^{\mathrm{b}}$ & $36.5 \pm 0.83^{\mathrm{a}}$ \\
Total saponins content, mg EE/g extract & $48.3 \pm 1.76^{\mathrm{a}}$ & $41.1 \pm 0.74^{\mathrm{b}}$ & $17.7 \pm 0.61^{\mathrm{c}}$ \\
Vitamin E, mg ATE/g extract & $0.49 \pm 0.027^{\mathrm{c}}$ & $2.54 \pm 0.059^{\mathrm{b}}$ & $3.11 \pm 0.11^{\mathrm{a}}$ \\
Vitamin C, mg AAE/g extract & $\mathrm{ND}$ & $\mathrm{ND}$ & $\mathrm{ND}$ \\
\hline
\end{tabular}

${ }^{\mathrm{a}-\mathrm{c}}$ means within a row bearing different letter are significantly different $(\mathrm{p}<0.05)$.

${ }^{\mathrm{d}} \mathrm{GAE}=$ gallic acid equivalents; $\mathrm{QE}=$ quercetin equivalents; $\mathrm{CE}=$ caffeine equivalents; $\mathrm{BCE}=\boldsymbol{\beta}$-carotene equivalents; $\mathrm{AE}=$ aescin equivalents; $\mathrm{ATE}=\alpha$-tocopherol equivalents; $\mathrm{ND}=$ not detected. ${ }^{\mathrm{e}}$ The composition is given as dry basis.

\subsection{Scavenging activity against DPPH and $\mathrm{ABTS}^{+}$radicals}

All purslane extracts and ascorbic acid could effectively scavenge the DPPH and the $\mathrm{ABTS}^{+}$radicals in concentrationdependent manners (Figure 2. and Figure 3.). At most concentrations used, ascorbic acid gave the highest inhibition activity against the DPPH and the $\mathrm{ABTS}^{+}$radicals compared with the same concentrations of purslane extracts. However, this difference was reduced at higher application levels, so that ascorbic acid and methanol extract had comparable scavenging activity at $500 \mu \mathrm{g} / \mathrm{mL}$ concentration $(98.2 \pm 0.89 \%$ vs. $97.3 \pm 1.46 \%$ for DPPH and $97.2 \pm 0.76 \%$ vs. $98.2 \pm 0.61 \%$ for $\mathrm{ABTS}^{+}$, respectively). In addition, methanol and ethanol extracts had greater scavenge capacity than that prepared by water. Also, scavenging action of methanol extract was higher than that of ethanol extract at all application levels, although the observed difference only reached significant levels against DPPH at 400 and $500 \mu \mathrm{g} / \mathrm{mL}$ concentrations and against $\mathrm{ABTS}^{+}$at 300 to $500 \mu \mathrm{g} / \mathrm{mL}$ concentrations. The scavenging of DPPH is based on the hydrogen donating ability of the antioxidant which leads to the formation of non-radical DPPH-H, while the scavenging of ABTS is involved in the electron transfer pathway that converts $\mathrm{ABTS}^{+}$to $\mathrm{ABTS}{ }^{[55]}$. Therefore, the higher scavenging ability of methanol extract can be related to its correspondingly higher levels of TPC, TFC, and TAC. The hydrogen-donating ability of phenolics to scavenge free radical can be characterized by the bond dissociation energy of $\mathrm{OH}$ bond ${ }^{[56]}$, whereas the electron-donating ability of these compounds seems to be associated with an extended electronic delocalization over the entire molecule ${ }^{[57]}$. Meanwhile, the higher scavenging activity of ethanol extract compared with water extract is very probably related to differences in the amounts of TCC, TSC, and vitamin E. A detailed study on the electron-donating capacity of carotenoids has been reported by Tan et al. ${ }^{[58]}$. They showed that the radical scavenging ability was mainly affected by the structural features in carotenoids, that is, the length of conjugated double bonds and participation of chemical groups on the $\beta$-ionone ring. Such structural differences also exist between and within the different classes of phenolic compounds and saponins ${ }^{[59}$, ${ }^{60]}$ and may contribute to the differences in scavenging capability of purslane extracts. 


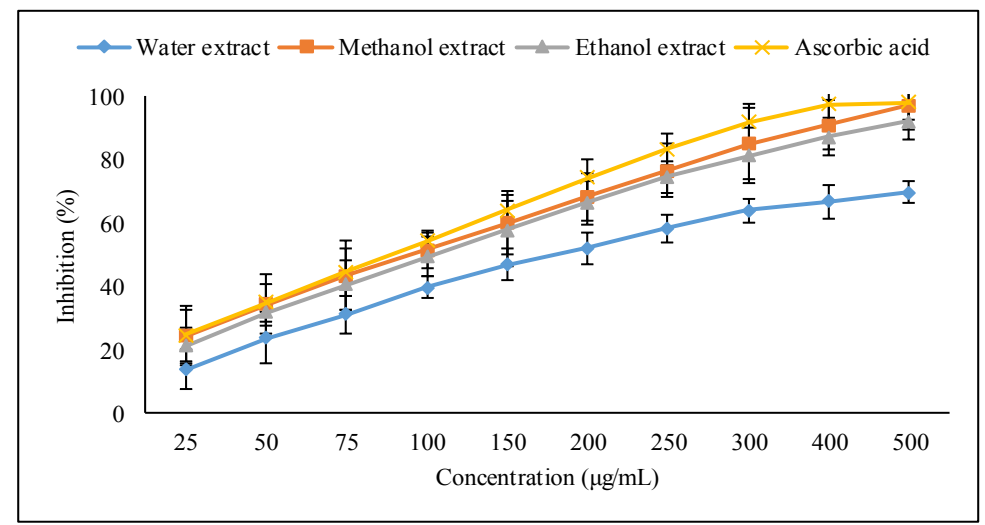

Figure 2. Percentage inhibition of DPPH radical by purslane extracts and ascorbic acid

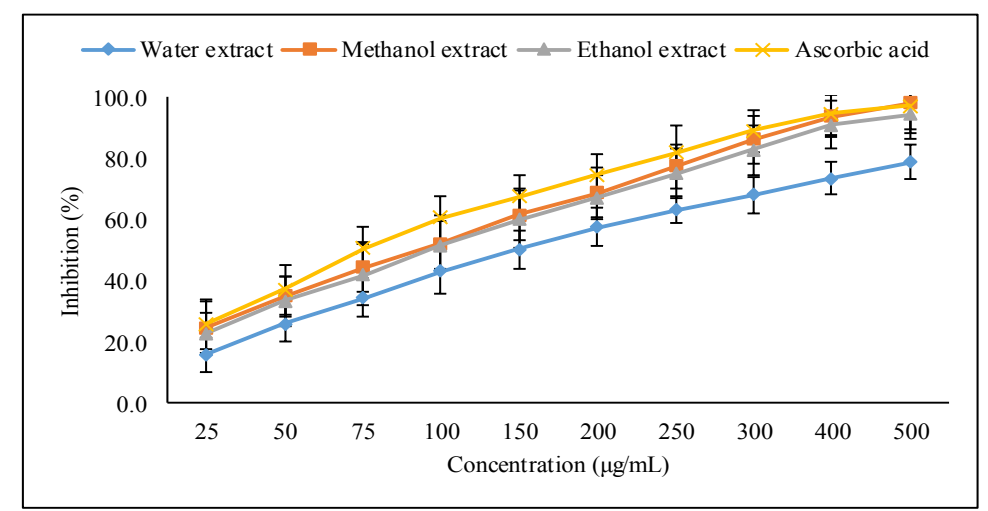

Figure 3. Percentage inhibition of $\mathrm{ABTS}^{+}$radical by purslane extracts and ascorbic acid

Our interpretations were proved by the significant negative correlations between the $\mathrm{IC}_{50}$ values of $\mathrm{DPPH}$ and ABTS radical-scavenging activity and the amounts of TPC $(\mathrm{r}=-0.73$ and -0.57 , respectively), TFC $(\mathrm{r}=-0.74$ and -0.60 , respectively), TAC ( $\mathrm{r}=-0.75$ and -0.59 , respectively), TCC $(\mathrm{r}=-0.61$ and -0.77 , respectively), or vitamin $\mathrm{E}(\mathrm{r}=-0.85$ and -0.94 , respectively), and significant positive correlations between the $\mathrm{DPPH}$ and $\mathrm{ABTS}^{+} \mathrm{IC}_{50}$ values and the amounts of $\operatorname{TSC}\left(\mathrm{r}=0.40\right.$ and 0.59 , respectively). The lower the $\mathrm{IC}_{50}$ value, the greater is the free radical scavenging capability of the plant extract. This is because a lower concentration is required for the antioxidant compounds to exhibit $50 \%$ of inhibition on free radicals. In both $\mathrm{DPPH}$ and $\mathrm{ABTS}^{+}$assays, $\mathrm{IC}_{50}$ values were found to be in order of ascorbic acid $<$ methanol extract $<$ ethanol extract $<$ water extract (Table 2.). Our $\mathrm{IC}_{50}$ values are close to those reported by Ercisli et al. ${ }^{[61]}$ and Taha and Osman ${ }^{[23]}$ for methanol $\left(116.3 \mu \mathrm{g} / \mathrm{mL}\right.$ for DPPH and $89.7 \mu \mathrm{g} / \mathrm{mL}$ for ABTS $\left.{ }^{+}\right)$and ethanol $(54.3 \mu \mathrm{g} / \mathrm{mL}$ for DPPH) extracts of purslane leaves, but they are much lower than the range (1300 to $3310 \mu \mathrm{g} / \mathrm{mL}$ for DPPH) reported by other researchers ${ }^{[4,45]}$. This variability in the results probably reflects differences in chemical composition between extracts, which is originated from several factors including extraction method, solvent type and solvent to solid ratio, extraction time and temperature as well as chemical composition and particle size of plant materials ${ }^{[45]}$. Differences in growth stages, genotype, harvesting times, and environmental conditions have been reported to contribute to purslane composition ${ }^{[4,22]}$.

Table 2. $\mathrm{IC}_{50}$ values $\left(\mathrm{mg} \mathrm{mL}^{-1}\right)$ of purslane extracts and ascorbic acid in DPPH, ABTS ${ }^{+}$, and lipid-peroxidation inhibition tests

\begin{tabular}{ccccc}
\hline Item & Water extract & Methanol extract & Ethanol extract & Ascorbic acid \\
\hline DPPH & $172.3 \pm 2.52^{\mathrm{a}}$ & $117.2 \pm 0.87^{\mathrm{c}}$ & $135.1 \pm 4.83^{\mathrm{b}}$ & $52.3 \pm 3.17^{\mathrm{d}}$ \\
ABTS $^{+}$ & $139.0 \pm 1.28^{\mathrm{a}}$ & $84.1 \pm 1.80^{\mathrm{c}}$ & $90.6 \pm 0.58^{\mathrm{b}}$ & $71.7 \pm 0.81^{\mathrm{d}}$ \\
Lipid-peroxidation & $284.6 \pm 8.80^{\mathrm{a}}$ & $153.0 \pm 2.29^{\mathrm{b}}$ & $109.2 \pm 3.76^{\mathrm{c}}$ & $284.5 \pm 1.45^{\mathrm{a}}$ \\
\hline
\end{tabular}

${ }^{a-d}$ Means within a row bearing different letter are significantly different $(p<0.05)$

\subsection{Lipid peroxidation inhibiting activity}


Peroxidation of linoleic acid was also inhibited by purslane extracts and ascorbic acid in concentration-dependent manners (Figure 4.). Like the two previous models, methanol and ethanol extracts did better results than water extract. On the other hand, the inhibitory effect of ethanol extract on linoleic acid peroxidation was more efficient compared with methanol extract. This is very likely due to higher levels lipophilic antioxidants in ethanol extract, as demonstrated by negative correlations between $\mathrm{IC}_{50}$ values of lipid peroxidation inhibitory activity and the amounts of $\mathrm{TCC}(\mathrm{r}=-0.94)$ or vitamin E $(\mathrm{r}=-0.99)$. In fact, the "polar paradox" described by Kulisic et al. ${ }^{[62]}$ might be illustrated here. According to this author, hydrophilic antioxidants are more active in lipophilic mediums whereas lipophilic antioxidants are more active in emulsions. Such an effect is probably caused by the fact that most polar antioxidants remain in the aqueous phase of the emulsion and are, thus, less effective in protecting the linoleic acid ${ }^{[63]}$. This effect was further confirmed in the present study, where ascorbic acid, as a well-known polar antioxidant compound, exerted less protective effect in this model. The lipid peroxidation inhibiting activity of ascorbic acid was much lower compared with methanol and ethanol extracts and did not significantly higher than that of the water extract at most levels used. $\mathrm{The} \mathrm{IC}_{50}$ values obtained in this model were found to be in the order of ethanol extract $<$ methanol extract $<$ ascorbic acid $\leq$ water extract. We could not find a reference that has explored the lipid peroxidation inhibiting effects of purslane extracts using the same procedure as employed in the present study. However, our interpretations are agreeing with the ones reported by Park et al. ${ }^{[64]}$, who evaluated the inhibitory effects of five purslane extracts on lipid peroxidation in a lipophilic medium, finding out that the lipid peroxidation inhibiting activity of water extract was significantly greater than that of petroleum ether, chloroform, ethyl acetate, and methanol extracts. Our results also confirm the findings of previous studies that showed that ascorbic acid has a moderate ability to prevent lipid peroxidation in emulsion-type systems ${ }^{[65,66]}$.

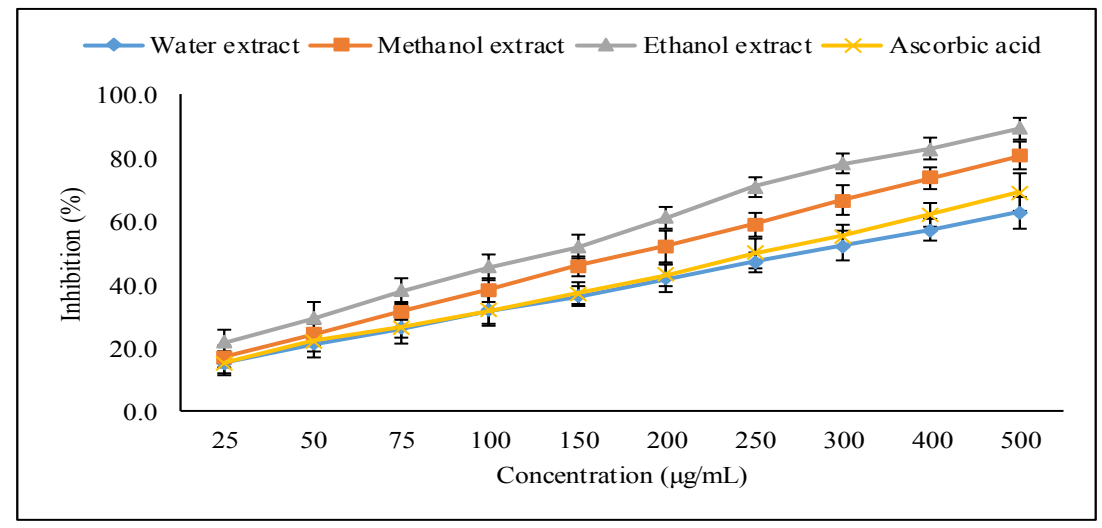

Figure 4. Percentage inhibition of lipid-peroxidation by purslane extracts and ascorbic acid

\subsection{Ferric reducing antioxidant power (FRAP)}

The FRAP values of tested materials was significantly different and found to be in the order of ascorbic acid $>$ methanol extract $>$ water extract $>$ ethanol extract (Figure 5.). The FRAP assay basically measures the reducing ability of antioxidants in a hydrophilic system, and lipid-soluble compounds are normally showed lower FRAP values than watersoluble components ${ }^{[63]}$. In addition, some compounds such as carotenoids has been reported to not contribute to the ferric reducing ability of extracts ${ }^{[67]}$. This effect was proved in this study by the significant negative correlation between the FRAP values and the amounts of TCC $(\mathrm{r}=-0.54)$. Inversely, the FRAP values were positively correlated with the amounts of TPC, TFC, and TAC ( $\mathrm{r}=0.86,0.82$, and 0.85 , respectively). Saponins were also found to have positive correlation $(r=0.73)$ with FRAP. These results are supported by the previous findings ${ }^{[18,37,45]}$, in which phenolic compounds of the purslane had a close relationship with the level of FRAP. In similar reports ${ }^{[28,37]}$ the higher amount of saponin compounds in plant extracts was correlated with their enhanced reducing potential, but to a lesser extent than that of phenolic compounds. These results probably reflect differences in the electron-donating and accepting properties of these biomolecules. 


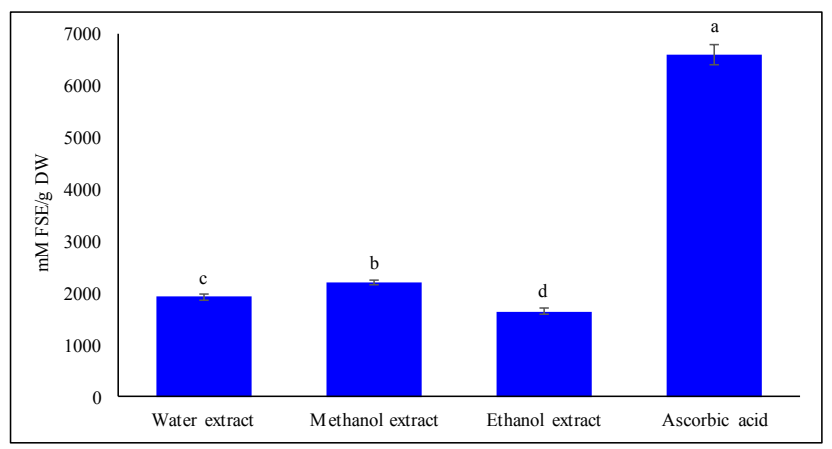

Figure 5. Ferric reducing/antioxidant power (FRAP) values of purslane extracts and ascorbic acid ${ }^{a-d}$ Means bearing different letter are significantly different $(p<0.05)$

\section{Conclusions}

There were significant differences in total phenolic, flavonoid, alkaloid, carotenoid, saponin, and vitamin E contents of purslane extracts. The methanol extract had greater phenolic, flavonoid, and alkaloid contents compared with water and ethanol extracts and the higher antioxidant activity of the methanol extract was verified by DPPH radical scavenging activity, $\mathrm{ABTS}^{+}$radical scavenging activity, and ferric reducing antioxidant power assays. Meanwhile, ethanol extract had the highest amounts of carotenoids and vitamin E contents and gave the most efficient inhibiting activity against ferrous chloride-induced oxidation of linoleic acid. On the other hand, water could water extract had the highest levels of solid and saponin contents and exhibited higher ferric reducing antioxidant power in comparison with ethanol extract. These differences in the characteristics of purslane extracts warrant further study, especially in regard to their effects on human and animals health. Also, more research is needed to adequately know the composition of the extracts, to identify the antioxidant compounds in the extracts, and to evaluate their potential as natural antioxidants.

\section{Author contributions}

MH took part in planning of the study, conducted the experiment, performed the statistical analysis of data, and prepared the manuscript. GS was the principal advisor and designed the study. AK was co-advisor, discussed the results and commented on the draft and final manuscript.

\section{Conflict of interest}

The authors declare that they do not have any conflict of interest.

\section{Acknowledgements}

This work was funded by University of Kurdistan. The authors would like to thank Dr. Salam A. Ibrahim (North Carolina Agricultural and Technical State University, Greensboro, NC, USA) for English language editing and Dr. Mohammad H. Romena (Razi University, Kermanshah, Iran) for technical assistance.

\section{References}

[1] WHO. Medicinal plants in Viet Nam, Western Pacific Series No 3. Hanoi, Viet Nam: WHO Regional Publications, Institute of Materia Medica; 1990.

[2] Chen B, Zhou H, Zhao W, et al. Effects of aqueous extract of Portulaca oleracea L. on oxidative stress and liver, spleen leptin, PAR $\alpha$ and FAS mRNA expression in high-fat diet induced mice. Molecular Biology Reports. 2012; 39(8): 7981-7988.

[3] Dkhil MA, Moniem AEA, Al-Quraishy S, et al. Antioxidant effect of purslane (Portulaca oleracea) and its mechanism of action. Journal of Medicinal Plants Research. 2011; 5(9): 1589-1593.

[4] Uddin MK, Juraimi AS, Ali ME, et al. Evaluation of antioxidant properties and mineral composition of purslane (Portulaca oleracea L.) at different growth stages. International Journal of Molecular Sciences. 2012; 13(8): 1025710267. 
[5] Shanker N, Debnath S. Impact of dehydration of purslane on retention of bioactive molecules and antioxidant activity. Journal of Food Science and Technology. 2015; 52(10): 6631-6638.

[6] Liu L, Howe P, Zhou YF, et al. Fatty acids and $\beta$-carotene in Australian purslane (Portulaca oleracea) varieties. Journal of Chromatography A. 2000; 893(1): 207-213.

[7] Petropoulos S, Karkanis A, Martins N, et al. Phytochemical composition and bioactive compounds of common purslane (Portulaca oleracea L.) as affected by crop management practices. Trends in Food Science and Technology. 2016; 55(9): 1-10.

[8] Agil R, Gilbert C, Tavakoli H, et al. Redefining unusable weeds to beneficial plants: Purslane as a powerful source of omega-3 for the future. Journal of Food Research. 2015; 4(6): 39-47.

[9] Sudhakar D, Kishore RK, Parthasarathy PR. Portulaca oleracea L. extract ameliorates the cisplatin-induced toxicity in chick embryonic liver. Indian Journal of Biochemistry and Biophysics. 2010; 47(3): 185-189.

[10] Hozayen W, Bastawy M, Elshafeey H. Effects of aqueous purslane (Portulaca oleracea) extract and fish oil on gentamicin nephrotoxicity in albino rats. Natural Science. 2011; 9(2): 47-62.

[11] Dias MG, Camões MFG, Oliveira L. Carotenoids in traditional Portuguese fruits and vegetables. Food Chemistry. 2009; 113(3): 808-815.

[12] Yue T, Xiaosa W, Ruirui Q, et al. The effects of Portulaca oleracea on hypoxia-induced pulmonary edema in mice. High Altitude Medicine \& Biology. 2015; 16(1): 43-51.

[13] Gong F, Li F, Zhang L, et al. Hypoglycemic effects of crude polysaccharide from purslane. International Journal of Molecular Sciences. 2009; 10(3): 880-888.

[14] Changizi-Ashtiyani S, Zarei A, Taheri S, et al. The effects of Portulaca oleracea alcoholic extract on induced hypercholesteroleomia in rats. Zahedan Journal of Research in Medical Sciences. 2013; 15(6): 34-39.

[15] Zidan Y, Bouderbala S, Djellouli F, et al. Portulaca oleracea reduces triglyceridemia, cholesterolemia, and improves lecithin: cholesterol acyltransferase activity in rats fed enriched-cholesterol diet. Phytomedicine. 2014; 21(12): 15041508.

[16] Okafor IA, Ayalokunrin MB, Orachu LA. A review on Portulaca oleracea (purslane) plant-Its nature and biomedical benefits. International Journal of Biomedical Research. 2014; 05(02): 75-80.

[17] Naeem F, Khan SH. Purslane (Portulaca oleracea L.) as phytogenic substance-A review. Journal of Herbs, Spices \& Medicinal Plants. 2013; 19(3): 216-232.

[18] Yang Z, Liu C, Xiang L, et al. Phenolic alkaloids as a new class of antioxidants in Portulaca oleracea. Phytotherapy Research. 2009; 23(7): 1032-1035.

[19] Erkan N. Antioxidant activity and phenolic compounds of fractions from Portulaca oleracea L. Food Chemistry. 2012; 133(3): 775-781.

[20] Zhang AH, Deng B, Jiang GB, et al. Preliminary study on antioxidant activity of flavone extractive from purslane. Journal of Food Science and Technology. 2008; 8: 140-143.

[21] Nagarani G, Abirami A, Nikitha P, et al. Effect of hydrothermal processing on total polyphenolics and antioxidant potential of underutilized leafy vegetables, Boerhaavia diffusa and Portulaca oleracea. Asian Pacific Journal of Tropical Biomedicine. 2014; 4(Suppl 1): S468-S477.

[22] Amirul Alam M, Juraimi AS, Rafii MY, et al. Effects of salinity and salinity-induced augmented bioactive compounds in purslane (Portulaca oleracea L.) for possible economical use. Food Chemistry. 2015; 169(2): 439-447.

[23] Taha H, Osman A. Assessment of antioxidant capacity of ethanolic extract of Portulaca oleracea leaves in vitro and in vivo. Journal of Medicinal Plants Research. 2015; 9(10): 335-342.

[24] Sharma A, Kaithwas G, Vijayakumar M, et al. Antihyperglycemic and antioxidant potential of polysaccharide fraction from Portulaca oleracea seeds against streptozotocin induced diabetes in rats. Journal of Food Biochemistry. 2012; 36(3): 378-382.

[25] Yang X, Yan Y, Li J, et al. Protective effects of ethanol extract from Portulaca oleracea L on dextran sulphate sodiuminduced mice ulcerative colitis involving anti-inflammatory and antioxidant. American Journal of Translational Research. 2016; 8(5): 2138-2148.

[26] Rinaldi R, Amodio ML, Colelli G. Effect of temperature and exogenous ethylene on the physiological and quality traits of purslane (Portulaca oleracea L.) leaves during storage. Postharvest Biology and Technology. 2010; 58(2): $147-156$.

[27] Iqbal S, Younas U, Chan KW, et al. Chemical composition of Artemisia annua L. leaves and antioxidant potential of extracts as a function of extraction solvents. Molecules. 2012; 17(5): 6020-6032.

[28] Pham HNT, Nguyen VT, Vuong QV, et al. Effect of extraction solvents and drying methods on the physicochemical and antioxidant properties of Helicteres hirsuta Lour. leaves. Technologies. 2015; 3(4): 285-301.

[29] Çelik SE, Özyürek M, Güçlü K, et al. Solvent effects on the antioxidant capacity of lipophilic and hydrophilic antioxidants measured by CUPRAC, ABTS/persulphate and FRAP methods. Talanta. 2010; 81(4-5): 1300-1309. 
[30] Peng S, Dai W, Yu H, et al. Antibacterial activity of aqueous and ethanolic extracts of Portulaca Oleracea L and Taraxacum mongolicum against pathogenic bacteria of cow mastitis. International Journal of Applied Research in Veterinary Medicine. 2014; 12(3): 210-213.

[31] Simopoulos AP, Norman HA, Gillaspy JE, et al. Common purslane: A source of omega-3 fatty acids and antioxidants. Journal of the American College of Nutrition. 1992; 11(4): 374-382.

[32] Hanan AA, Sobhy MH, Kawkab AA, et al. Chemical and remedial effects of purslane (Portulaca oleracea) plant. Life Science Journal. 2014; 11(6): 31-42.

[33] Sallam EM, Anwar MM. Antioxidant activity of some extracts from gamma irradiated purslane (Portulaca oleracea) plant. International Journal of Agriculture and Biology. 2017; 19(1): 48-52.

[34] Zhou K, Yu L. Total phenolic contents and antioxidant properties of commonly consumed vegetables grown in Colorado. LWT-Food Science and Technology. 2006; 39(10): 1155-1162.

[35] Abu Bakar MF, Mohamed M, Rahmat A, et al. Phytochemicals and antioxidant activity of different parts of bambangan (Mangifera pajang) and tarap (Artocarpus odoratissimus). Food Chemistry. 2009; 113(2): 479-483.

[36] John B, Sulaiman CT, George S, et al. Spectrophotometric estimation of total alkaloids in selected Justicia species. International Journal of Pharmacy and Pharmaceutical Sciences. 2014; 6(5): 647-648.

[37] Vuong QV, Hirun S, Roach PD, et al. Effect of extraction conditions on total phenolic compounds and antioxidant activities of Carica papaya leaf aqueous extracts. Journal of Herbal Medicine. 2013; 3(3): 104-111.

[38] Awe FB, Fagbemi TN, Ifesan BO, et al. Antioxidant properties of cold and hot water extracts of cocoa, hibiscus flower extract, and ginger beverage blends. Food Research International. 2013; 52(2): 490-495.

[39] Kayden HJ, Chow CK, Bjornson LK. Spectrophotometric method for determination of tocopherol in red blood cells. Journal of Lipid Research. 1973; 14(5): 533-540.

[40] Moon JK, Shibamoto T. Antioxidant assays for plant and food components. Journal of Agricultural and Food Chemistry. 2009; 57(5): 1655-1666.

[41] Wong-Paz JE, Contreras-Esquivel JC, Rodríguez-Herrera R, et al. Total phenolic content, in vitro antioxidant activity and chemical composition of plant extracts from semiarid Mexican region. Asian Pacific Journal of Tropical Medicine. 2015; 8(2): 104-111.

[42] Huang D, Ou B, Prior RL. The chemistry behind antioxidant capacity assays. Journal of Agricultural and Food Chemistry. 2005; 53(6): 1841-1856.

[43] Benzie IF, Strain JJ. Ferric reducing/antioxidant power assay: Direct measure of total antioxidant activity of biological fluids and modified version for simultaneous measurement of total antioxidant power and ascorbic acid concentration. Methods in Enzymology. 1999; 299: 15-27.

[44] SAS Institute. SAS User's Guide, Release 9.1. Cary, North Carolina, USA: SAS Institute Inc; 2003.

[45] Lim YY, Quah EP. Antioxidant properties of different cultivars of Portulaca oleracea. Food Chemistry. 2007; 103(3): 734-740.

[46] Naczk M, Shahidi F. Extraction and analysis of phenolics in food. Journal of chromatography A. 2004; 1054(1-2): 95111.

[47] Tan MC, Tan CP, Ho CW. Effects of extraction solvent system, time and temperature on total phenolic content of henna (Lawsonia inermis) stems. International Food Research Journal. 2013; 20(6): 3117-3123.

[48] Ko MJ, Cheigh CI, Chung MS. Relationship analysis between flavonoids structure and subcritical water extraction (SWE). Food chemistry. 2014; 143: 147-155.

[49] Yao L, Jiang Y, Datta N, et al. HPLC analyses of flavanols and phenolic acids in the fresh young shoots of tea (Camellia sinensis) grown in Australia. Food Chemistry. 2004; 84(2): 253-263.

[50] Lee MY, Lee MK, Park I. Inhibitory effect of onion extract on polyphenol oxidase and enzymatic browning of taro (Colocasia antiquorum var. esculenta). Food Chemistry. 2007; 105(2): 528-532.

[51] Kato Y, Suga N. Covalent adduction of endogenous and food-derived quinones to a protein: its biological significance. Journal of Clinical Biochemistry and Nutrition. 2018; 62(3): 213-220.

[52] Lee YL, Jian SY, Lian PY, et al. Antioxidant properties of extracts from a white mutant of the mushroom Hypsizigus marmoreus. Journal of Food Composition and Analysis. 2008; 21(2): 116-124.

[53] Frederick N, Mani J. Phytochemical screening and in-vitro antioxidant activity of different solvent extracts of Musa rasthali fruit. International Journal of Chemical Sciences. 2016; 5(3): 54-70.

[54] Böttcher S, Drusch S. Saponins-Self-assembly and behavior at aqueous interfaces. Advances in Colloid and Interface science. 2017; 243:105-113.

[55] Kaviarasan S, Naik GH, Gangabhagirathi R, et al, Priyadarsini KI. In vitro studies on antiradical and antioxidant activities of fenugreek (Trigonella foenum graecum) seeds. Food Chemistry. 2007; 103(1): 31-37.

[56] Rajendran M, Ravichandran R, Devapiriam D. Molecular modeling study of quercetin and their metal complexes. International Journal of Computer Applications. 2012; 50(22): 30-34. 
[57] Sadasivam K, Kumaresan R. A comparative DFT study on the antioxidant activity of apigenin and scutellarein flavonoid compounds. Molecular Physics. 2011; 109(6): 839-852.

[58] Tan C, Xue J, Abbas S, et al. Liposome as a delivery system for carotenoids: comparative antioxidant activity of carotenoids as measured by ferric reducing antioxidant power, DPPH assay and lipid peroxidation. Journal of Agricultural and Food Chemistry. 2014; 62(28): 6726-635.

[59] Balasundram N, Sundram K, Samman S. Phenolic compounds in plants and agri-industrial by-products: antioxidant activity, occurrence, and potential uses. Food Chemistry. 2006; 99(1): 191-203.

[60] Navarro del Hierro J, Herrera T, Fornari T, et al. The gastrointestinal behavior of saponins and its significance for their bioavailability and bioactivities. Journal of Functional Foods. 2018; 40: 484-497.

[61] Ercisli S, Coruh I, Gormez A, et al. Antioxidant and antibacterial activities of Portulaca oleracea L. grown wild in Turkey. Italian Journal of Food Science. 2008; 20(4): 533-542.

[62] Kulisic T, Radonic A, Katalinic V, et al. Use of different methods for testing antioxidative activity of oregano essential oil. Food Chemistry. 2004; 85(4): 633-640.

[63] Apak R, Güçlü K, Demirata B, et al. Comparative evaluation of various total antioxidant capacity assays applied to phenolic compounds with the CUPRAC assay. Molecules. 2007; 12(7): 1496-1547.

[64] Park SH, Kim DK, Bae JH. The antioxidant effect of Portulaca oleracea extracts and its antimicrobial activity on Helicobacter pylori. Korean Journal of Food And Nutrition. 2011; 24(3): 306-311.

[65] Liang CH, Chan LP, Ding HY, et al. Free radical scavenging activity of 4-(3,4-dihydroxybenzoyloxymethyl) phenylO- $\beta$-D-glucopyranoside from Origanum vulgare and its protection against oxidative damage. Journal of Agricultural and Food Chemistry. 2012; 60(31): 7690-7696.

[66] Zadra M, Piana M, Brum TFD, Boligon AA, Freitas RBD, Machado MM, Stefanello ST, Soares FAA, Athayde ML. Antioxidant activity and phytochemical composition of the leaves of Solanum guaraniticum A. St.-Hil. Molecules. 2012; 17(11): 12560-12574.

[67] Ou B, Hampsch-Woodill M, Prior RL. Development and validation of an improved oxygen radical absorbance capacity assay using fluorescein as the fluorescent probe. Journal of Agricultural and Food Chemistry. 2001; 49(10): 4619-4626.

[68] Güçlü-Üstündağ Ö, Mazza G. Saponins: properties, applications and processing. Critical Reviews in Food Science and Nutrition. 2007; 47(3): 231-258. 